\title{
Urinary Concentrations of Alpha-1-Microglobulin and Albumin in Patients with Reflux Nephropathy before and after Puberty
}

\author{
Ryuichiro Konda ${ }^{a}$ Hidehiro Kakizaki ${ }^{b}$ Hideo Nakaic Yutaro Hayashid \\ Shozo Hosokawa Satoru Kawaguchif Hirofumi Matuokag \\ Katsuya Nonomurab \\ (Reflux Nephropathy Forum, J apan Prospective Study Group)
}

\begin{abstract}
${ }^{a}$ Department of Urology, Tohoku University School of Medicine; bepartment of Urology, Hokkaido University School of Medicine; 'Department of Urology, Tokyo Metropolitan Kiyose Children's Hospital; dDepartment of Urology, Nagoya City University Medical School; eDepartment of Urology, Osaka Medical Center and Research

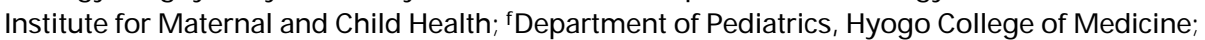

gDepartment of Urology, Fukuoka University School of Medicine, J apan
\end{abstract}

\section{Key Words}

Vesicoureteral reflux $\cdot$ Age $\cdot$ Gender $\cdot \alpha_{1}$-Microglobulin . Albumin

\begin{abstract}
We determined urinary concentrations of $\alpha_{1}$-microglobulin and albumin in 155 patients with reflux nephropathy including 72 prepubertal (48 males and 24 females) and 83 postpubertal patients (43 males and 40 females) to elucidate the effect of age and gender in the progression of renal damage. Vesicoureteral reflux was resolved in all patients at least two years before enrollment into this study. Renal scarring was diagnosed with 99mtechnetium dimercaptosuccinic acid renal scan. More severe renal scarring was found predominantly in male compared to female patients. Urinary $\alpha_{1}$-microglobulin levels were significantly lower in postpubertal female patients (mean \pm SD: $1.59 \pm 1.02 \mathrm{mg} / \mathrm{g}$ creatinine) than in prepubertal males and females $(3.32 \pm 3.53$ and $4.06 \pm 4$, respectively; $p<0.007$ and $p<0.002$, respectively), and in postpu-
\end{abstract}

\section{KARGER}

Fax +41613061234 E-Mail karger@karger.ch www. karger.com

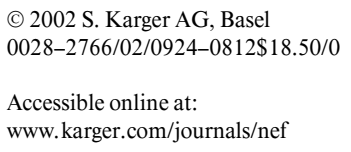

bertal males (3.69 $\pm 2.6 ; p<0.002)$ regardless of severity of renal scarring. In the patients with severe unilateral renal scarring, urinary albumin levels were significantly higher in postpubertal males $(81.9 \pm 239.5)$ than in prepubertal males and postpubertal females $(25.8 \pm 63.1$ and $13.8 \pm 7.7$, respectively; $p<0.05$ and $p<0.05$, respectively). Our results suggest that glomerular injury may develop during adolescence predominantly in male patients with severe renal scarring. In contrast, renal damage indicated by urinary $\alpha_{1}$-microglobulon level appears to be ameliorated in female postpubertal patients. This gender difference may be attributed to sex hormones.

Copyright $\odot 2002$ S. Karger AG, Basel

\section{Introduction}

Reflux nephropathy is an important renal disease resulting in hypertension, chronic renal insufficiency, and chronic renal failure in childhood and youth [1-3]. In 
some patients with reflux nephropathy, renal damage progresses with increasing age even after resolution of vesicoureteral reflux [1, 3-5]. A gender difference is observed in the progression of renal damage; males with reflux nephropathy have more severe renal involvement and are more likely to reach end-stage renal failure [3, 4, 6-8]. Proteinuria is one of the critical signs for these patients who develop progression of renal damage [1]. Since an increase of urinary protein excretion indicates the presence of glomerular pathology, proteinuria is a poor prognostic feature in patients with reflux nephropathy [1, 9, 10]. $\alpha_{1}$-Microglobulin is a sensitive marker of renal tubular function and a useful tool to predict the progression of renal damage in patients with reflux nephropathy [9]. We found deterioration of renal function and/or an increase of urinary albumin level with age in children with reflux nephropathy who had high levels of urinary $\alpha_{1}$-microglobulin during the follow-up period [9].

To elucidate the effect of age and gender on the progression of renal injury, we examined urinary $\alpha_{1}$-microglobulin and urinary albumin levels in male and female patients with reflux nephropathy before and after puberty. Renal scarring was estimated by $99 \mathrm{~m}$ technetium dimercaptosuccinic acid (DMSA) renal scan.

\section{Materials and Methods}

From 1997 to 1998 , a total of 155 children including 92 boys and 63 girls who had renal scarring on DMSA renal scan were enrolled from 6 centers participating in this study. Since the purpose of this study was to elucidate the effects of age and gender on the progression of renal injury, we examined 72 children ( 49 boys and 23 girls) with reflux nephropathy aged 6-10 years (prepubertal group), and 83 children (43 boys and 40 girls) aged 14-18 years (postpubertal group). Pubertal status was measured by Tanner staging. Most of the patients in the postpubertal group attained puberty before enrollment in this study. 146 patients (94\%) including 69 prepubertal patients were investigated because of urinary tract infection, and 9 $(6 \%)$ for other causes such as urinary incontinence, hydronephrosis on ultrasound examination or microhematuria. Hypertension was found in 4 prepubertal patients (systolic blood pressure: 118$140 \mathrm{~mm} \mathrm{Hg}$ ) and 7 postpubertal cases (120-140). We showed the side of ureters with reflux and the distribution of reflux grades at the initial investigation in table 1 . Vesicoureteral reflux was treated surgically in 146 patients including 5 prepubertal cases. Reflux resolved in all cases including 9 patients managed conservatively at least 2 years before enrollment in the study. Resolution of reflux was defined as the absence of reflux on two consecutive voiding cystourethrographies performed before this study started. All examinations were performed only after the patients and/or their parents gave informed consent to participate.

Serum and spot urine samples were obtained simultaneously in the morning to determine serum creatinine, urinary $\alpha_{1}$-microglobu-
Table 1. Radiographic findings at the initial investigation

\begin{tabular}{lllr}
\hline Age & $6-10$ years & $14-18$ years & Total \\
\hline Patients & 72 & 83 & \\
Reflux & & & \\
$\quad$ Bilateral & 44 & 57 & 101 \\
$\quad$ Unilateral & 28 & 26 & 54 \\
$\quad$ Right & 12 & 15 & 27 \\
$\quad$ Left & 16 & 11 & 27 \\
\hline
\end{tabular}

\section{Ureters with reflux}

Grade of reflux

\begin{tabular}{crrr}
1 & 6 & 5 & 11 \\
2 & 17 & 27 & 44 \\
3 & 32 & 56 & 88 \\
4 & 50 & 47 & 97 \\
5 & 10 & 6 & 16 \\
\hline Total & 140 & 116 & 256 \\
\hline
\end{tabular}

lin, urinary albumin, and urinary creatinine levels. Urinary $\alpha_{1^{-}}$ microglobulion and albumin levels were measured using commercially available kits, and were expressed in $\mathrm{mg} / \mathrm{g}$ creatinine to minimize the effect of diuresis. Urinalysis and/or urine culture was performed using the same spot urine samples. No urinary tract infection was detected. No febrile episode due to urinary tract infection was documented in any of the patients after resolution of reflux.

Two hours after intravenous injection of DMSA, renal scans were performed using a digital camera and the data were processed with a commercially available kit. Images of postereoanterior and posterior oblique projections were recorded by a gamma camera computer system equipped with a pinhole collimator. The degree of renal scarring in each kidney was classified according to the findings on DMSA renal scans (fig. 1): 'mild' denotes no more than two scarred areas; and 'severe' signifies a large scar extending over half or more of the renal cortex, or small-sized kidney. In all cases, DMSA renal scans were performed within 3 months before or after the measurement of serum and urinary markers.

Data are presented as mean \pm SD. Statistical analysis of the results was performed by Man-Whitney U test or Fisher's PLSD test. $\mathrm{p}<0.05$ was considered significant. StatView for Macintosh was used for statistical analysis.

\section{Results}

We classified the severity of renal scarring in each patient enrolled in this study into three grades according to the degree of renal scarring on DMSA renal scans (fig. 1; table 2). Sixty patients including 28 prepubertal children had mild scarring in unilateral or bilateral kidneys (grade 1). Ninety-two patients including 42 prepubertal children had severe renal scarring unilaterally with or without mild scarring in the contralateral kidney (grade 

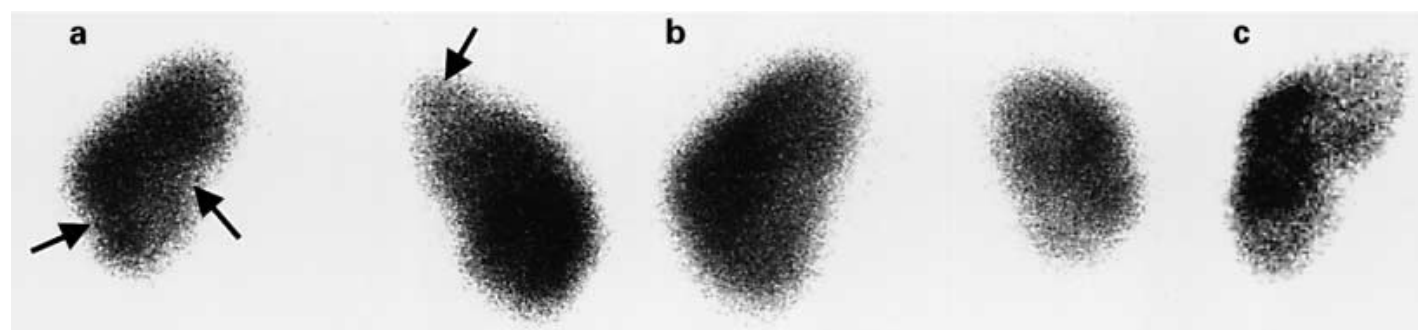

Fig. 1. Representative cases illustrating three grades of renal scarring according to findings on DMSA renal scans. a Mild scarring (arrow) is found in bilateral kidneys (grade 1). b Severe renal scarring (small-sized kidney) is found in right kidney (grade 2). c Bilateral kidneys show severe renal scarring extending over half of renal cortex (grade 3).

Table 2. Scarring grade before and after puberty

\begin{tabular}{lllc}
\hline Age & $6-10$ years & $14-18$ years & Total \\
\hline Patients & 72 & 83 & 155 \\
Male & 49 & 43 & 92 \\
Female & 23 & 40 & 63 \\
\hline
\end{tabular}

Ratio of males to females (total)

Scarring grade

\begin{tabular}{cccc}
1 & $14: 14(28)$ & $12: 20(32)$ & $26: 34(60)$ \\
2 & $34: 9(43)$ & $30: 19(49)$ & $64: 28(92)$ \\
3 & $1: 0(1)$ & $1: 1(2)$ & $2: 1(3)$ \\
Total & $49: 23(72)$ & $43: 40(83)$ & $92: 63(155)$ \\
\hline
\end{tabular}

2). Only 3 cases showed severe renal scarring bilaterally (grade 3), including one prepubertal case.

The proportion of the renal scarring grades was exactly the same in the prepubertal and postpubertal patients (table 2). A high grade of renal scarring (grades 2 and 3 ) was found in $72 \%$ of male patients (66/92) and $46 \%$ of females $(29 / 63)$ (table 2). The grade of renal scarring was significantly lower in the female compared with the male patients $(p<0.007)$. Serum creatinine was at a normal level in all cases including three with grade 3 renal scarring. Mean $\pm \mathrm{SD}$ of serum creatinine level in the patients with grade 1 and 2 renal scarring was $0.5 \pm 0.3 \mathrm{mg} / \mathrm{dl}$ (range 0.3-0.7) and $0.4 \pm 0.1$ (range 0.3-0.6) before puberty, respectively, and $0.6 \pm 0.2$ (range 0.4-0.9) and $0.6 \pm 0.2$ (range $0.4-1$ ) after puberty, respectively. There was no significant difference in serum creatinine level between the patients with grade 1 and 2 renal scarring in both groups. In the patients with grade 3 renal scarring, levels of serum creatinine were 0.5 in one case before puberty, and 0.8 and 0.9 in two after puberty.
Table 3. Urinary $\alpha_{1}$-microglobulin and urinary albumin before and after puberty (excluding three patients in group 3)

\begin{tabular}{lll}
\hline & Before puberty & After puberty \\
\hline Age, years & $6-10$ & $14-18$ \\
Urinary $\alpha$-microglobulin & & \\
$\quad$ Male & $3.32 \pm 3.53$ & $3.69 \pm 2.6$ \\
$\quad$ Female & $4.06 \pm 4$ & $1.59 \pm 1.02^{\mathrm{a}, \mathrm{b}, \mathrm{c}}$ \\
Urinary albumin & & \\
$\quad$ Male & $22.2 \pm 53.4$ & $63.0 \pm 30.8$ \\
$\quad$ Female & $21.3 \pm 18.9$ & $17.6 \pm 16.7$ \\
\hline
\end{tabular}

a,b Versus male patients before (a) and after (b) puberty, $\mathrm{p}<0.007$ and $\mathrm{p}<0.002$, respectively.

c Versus female patients before puberty, $\mathrm{p}<0.002$.

As there were only 3 patients with grade 3 renal scarring, the differences between male and female patients before and after puberty were analyzed only in those with grade 1 and 2 renal scarring (table 3 ). Urinary $\alpha_{1}$-microglobulin levels were significantly lower in postpubertal female patients $(1.59 \pm 1.02)$ compared with prepubertal males and females $(3.32 \pm 3.53$ and $4.06 \pm 4$, respectively), and with postpubertal males (3.69 \pm 2.6 ; $p<0.007$, $\mathrm{p}<0.002$ and $\mathrm{p}<0.002$, respectively). Although urinary albumin levels inclined to be higher in male patients before puberty $(63.0 \pm 30.8)$ compared with males and females before puberty $(22.2 \pm 53.4$ and $21.3 \pm 18.9$, respectively), and females after puberty (17.6 \pm 16.7$)$, a significant difference was not observed (table 3 ).

The difference between male and female patients was examined in those with grade 1 and 2 renal scarring (table 4). Urinary $\alpha_{1}$-microglobulin levels were significantly lower in postpubertal female patients with grade 1 renal 
Table 4. Urinary $\alpha_{1}$-microglobulin and urinary albumin in the patients with grade 1 and 2 renal scarring

\begin{tabular}{|c|c|c|c|c|}
\hline & \multicolumn{2}{|c|}{ Before puberty (6-10 years) } & \multicolumn{2}{|c|}{ After puberty (14-18 years) } \\
\hline & grade 1 & grade 2 & grade 1 & grade 2 \\
\hline \multicolumn{5}{|c|}{ Urinary $\alpha_{1}$-microglobulin } \\
\hline Male & $3.86 \pm 5.45$ & $3.09 \pm 2.43$ & $3.00 \pm 1.67$ & $3.97 \pm 2.87$ \\
\hline Female & $3.37 \pm 3.58$ & $5.13 \pm 4.59$ & $1.62 \pm 1.05^{\mathrm{a}, \mathrm{b}, \mathrm{c}}$ & $1.56 \pm 1.02^{\mathrm{d}, \mathrm{e}, \mathrm{f}}$ \\
\hline \multicolumn{5}{|c|}{ Urinary albumin } \\
\hline Male & $13.8 \pm 8.2$ & $25.8 \pm 63.1$ & $19.3 \pm 28.8$ & $81.9 \pm 239.5^{\mathrm{g}, \mathrm{h}}$ \\
\hline Female & $18.8 \pm 18.4$ & $25.2 \pm 20.3$ & $21.2 \pm 22.1$ & $13.8 \pm 7.7$ \\
\hline
\end{tabular}

a,b,c Versus prepubertal male patients with grade 1 renal scarring, and versus prepubertal females and postpubertal males with grade 2 scarring, $p<0.03, p<0.004$ and $p<0.006$, respectively.

d,e,f Versus prepubertal male patients with grade 1 renal scarring, and versus prepubertal females and postpubertal males with grade 2 scarring, $p<0.03, p=0.003$ and $p<0.006$, respectively.

g,h Versus prepubertal male and postpubertal female patients with grade 2 renal sarring, $\mathrm{p}<$ 0.05 and $\mathrm{p}<0.05$, respectively. scarring $(1.62 \pm 1.05)$ than in prepubertal males with grade $1(3.86 \pm 5.45)$, and prepubertal females and postpubertal males with grade $2(5.13 \pm 4.59$ and $3.97 \pm$ 2.87, respectively) ( $\mathrm{p}<0.03, \mathrm{p}<0.004$ and $\mathrm{p}<0.006$, respectively). Significantly lower levels of urinary $\alpha_{1}$ microglobulin was found in postpubertal female patients with grade 2 renal scarring $(1.56 \pm 1.02)$ compared with prepubertal males with grade 1 , and prepubertal females and postpubertal males with grade $2(\mathrm{p}<0.03, \mathrm{p}=0.003$ and $\mathrm{p}<0.006$, respectively). Urinary albumin levels were significantly higher in postpubertal male patients with grade 2 renal scarring $(81.9 \pm 239.5)$ than in prepubertal males and postpubertal females with grade $2(25.8 \pm 63.1$ and $13.8 \pm 7.7$, respectively) $(\mathrm{p}<0.05$ and $\mathrm{p}<0.05$, respectively). Levels of urinary albumin in postpubertal males with grade 2 renal scarring were higher than in prepubertal males and females with grade 1 scarring (13.8 \pm 8.2 and $18.8 \pm 18.4$, respectively), prepubertal females with grade 2 scarring $(25.2 \pm 20.3)$ and postpubertal males and females with grade 1 renal scarring (19.3 \pm 28.8 and $21.2 \pm 22.1$, respectively) although a significant difference was not found by Mann-Whitney U test or Fisher's PLSD test.

\section{Discussion}

A gender difference was found in the grade of renal scarring, which was higher in male than in female patients. Furthermore, levels of urinary $\alpha_{1}$-microglobulin
Table 5. Centers participating in this study

\begin{tabular}{|c|c|c|}
\hline Centers & City & Principal investigator \\
\hline Hokkaido University & Sapporo & Hidehiro Kakizaki \\
\hline Tohoku University & Sendai & Ryuichiro Konda \\
\hline \multicolumn{3}{|l|}{ Tokyo Metropolitan Kiyose } \\
\hline Children's Hospital & Kiyose & Hideo Nakai \\
\hline Toyokawa City Hospital & Toyokawa & Masayuki Tsugaya \\
\hline Nagoya City University & Nagoya & Yutaro Hayashi \\
\hline Fukuoka University & Fukuoka & Hirofumi Matsuoka \\
\hline
\end{tabular}

after puberty were significantly lower in female patients than in males. In the male patients, a higher level of urinary albumin was found in the cases after puberty compared with those before puberty. In contrast, no significant difference was seen in the female patients before and after puberty. These results agree with other studies that have reported a high incidence of severe renal damage in male patients with reflux nephropathy $[3,4,6,7]$. Although renal function in the patients with chronic renal diseases tends to deteriorate faster in male than in female patients [11-15], this gender difference is not found in prepubertal cases [11]. The authors of these studies suggest that sex hormones contribute to the gender difference in the progression of renal damage. In the present study, no significant gender difference was seen in urinary $\alpha_{1^{-}}$ microglobulin and albumin in the patients before puberty. 
Before starting this study, we expected an increase of urinary albumin and $\alpha_{1}$-microglobulin in postpubertal patients compared with prepubertal children because renal damage is thought to progress with age increase in patients with reflux nephropathy. In this study, however, we found significantly lower urinary $\alpha_{1}$-microglobulin levels in postpubertal females than in prepubertal females. Urinary albumin levels were inclined to be higher in postpubertal than in prepubertal male patients and a significant difference was found between the males with grade 2 renal scarring before and after puberty. In contrast, female patients before and after puberty had similar urinary albumin levels. These results imply that glomerular injury progresses during adolescence predominantly in male patients.

Although this study is not a prospective survey of renal function, our findings suggest that renal function in female patients with reflux nephropathy may rarely deteriorate with age increase, but rather ameliorates after puberty. In contrast, glomerular injury is inclined to progress after puberty in male patients. Sex hormones may influence the evolution of renal damage in the patients with reflux nephropathy as in other renal diseases $[11,12$, 15]. The renin-angiotensin system (RAS) is one of the principal factors that promote renal disease progression
[16]. Expression of renin is upregulated in the scarred kidneys secondary to urinary tract diseases [17]. Estrogen can interfere with the vascular response to angiotensin II and blunt the increase of intraglomerular pressure induced by angiotensin II [18]. In addition to hemodynamic effects, angiotensin II can modulate both synthetic and degradation processes of extracellular matrix through the modulation of fibrogenic cytokines including transforming growth factor- $\beta$ and platelet-derived growth factor [16]. Interleukin 6 is one of several critical factors that exacerbate tubulointerstitial injury in a variety of renal diseases including reflux nephropathy $[19,20]$. Estrogen can inhibit the production of interleukin 6 by bone marrow-derived stromal cells and osteoblasts, although it is not clear whether estrogen affects the production of interleukin 6 by the kidneys [21]. We suggest that estrogen may show its beneficial effect on the prevention of renal disease progression in part through the regulation of RAS and the production of cytokines. In an on-going follow-up study, we continue to monitor the renal function of the 72 patients with reflux nephropathy before puberty enrolled in the present study, to prove or disprove our hypothesis that renal damage progresses with increasing age predominantly in male patients, while renal function does not deteriorate, but even improves, after puberty in female patients.

\section{References}

1 Bailey RR: Vesico-ureteric reflux and reflux nephropathy. Kidney Int 1993;42:S80-S85.

2 Fivush BA, Jabs K, Neu AM, Sullivan EK, Feld L, Kohaut E, Fine R: Chronic renal insufficiency in children and adolescence: The 1996 annual report of NAPRTCS. Pediatr Nephrol 1998;12:328-337.

3 Dillon MJ, Goonasekera CDA: Reflux nephropathy. J Am Soc Nephrol 1998;9:23772383.

4 Zhang Y, Bailey RR: A long term follow up of adults with reflux nephropathy. $\mathrm{Nz}$ Med J 1995;108:142-144.

5 Jacobson SH, Eklof O, Eriksson CG, Lins LE, Tidgren B, Winberg J: Development of hypertension and uraemia after pyelonephritis in childhood: 27 year follow up. Br Med J 1989; 299:703-706.

6 Hiraoka M, Hori C, Tsukahara H, Kasuga K, Ishihara Y, Sudo M: Congenital small kidneys with reflux as a common cause of nephropathy in boys. Kidney Int 1997;52:811-816.

7 Assael BM, Guez S, Marra G, Secco M, Manzoni G, Bosio M, Pelegatta A, Acerbi L, Delli'Agnola CA, Selvaggio G, Vegni M, Cecchetti V, Cucchi L: Congenital reflux nephropathy: A follow-up of 108 cases diagnosed perinatally. Br J Urol 1998;82:252-257.

8 Risdon RA, Yeung CK, Ransley PG: Reflux nephropathy in children submitted to unilater- al nephrectomy: A clinicopathological study. Clin Nephrol 1993;40:308-314.

9 Konda R, Sakai K, Ota S, Takeda A, Orikasa S: Follow-up study of renal function in children with reflux nephropathy after resolution of vesicoureteral reflux. J Urol 1997;157:975-979.

10 Matsuoka H, Oshima K, Sakamoto K, Taguchi $\mathrm{T}$, Takebayashi S: Renal pathology in patients with reflux nephropathy. Eur Urol 1994;26: 153-159.

11 Gretz N, Zeier M, Geberth S, Strauch M, Ritz E: Is gender a determinant for evolution of renal failure? A study in autosomal dominant polycystic kidney disease. Am J Kidney Dis 1989; 14:178-183.

12 Coggins CH, Lewis JB, Caggiula AW, Castaldo LS, Klahr S, Wang SR: Difference between women and men with chronic renal disease. Nephrol Dial Transplant 1998;13:1430-1437.

13 Hannedouche T, Chauveau P, Kalou F, Albouze G, Lacour B, Jungers P: Factors affecting progression in advanced chronic renal failure. Clin Nephrol 1993;39:312-320.

14 Jungers P, Chauveau P, Descamps-Latscha B, Labrunie M, Giraud E, Man NK, Grunfeld JP, Jacobs C: Age- and gender-related incidence of chronic renal failure in a French urban area: A prospective epidemiologic study. Nephrol Dial Transplant 1996;11:1542-1546.
15 Neugarten J, Acharya A, Silbiger SR: Effect of gender on the progression of nondiabetic renal disease: A meta-analysis. J Am Soc Nephrol 2000;11:319-329.

16 Matsusaka T, Hymes J, Ichikawa I: Angiotensin in progressive renal diseases: Theory and practice. J Am Soc Nephrol 1996;7:20252043.

17 Konda R, Orikasa S, Sakai K, Ota S, Kimura $\mathrm{N}$ : The distribution of renin containing cells in scarred kidneys. J Urol 1996;156:1450-1454.

18 Miller JA, Anacta LA, Cattran DC: Impact of gender on the renal response to angiotensin II. Kidney Int 1999;55:278-285.

19 Fukatsu A, Matsuo S, Yuzawa Y, Miyai H, Futenma A, Kato K: Expression of interleukin 6 and major histocompatibility complex molecules in tubular epithelial cells of diseased human kidneys. Lab Invest 1993;69:58-67.

20 Wang J, Konda R, Sato H, Sakai K, Ito S, Orikasa $\mathrm{S}$ : Clinical significance of urinary interleukin-6 in children with reflux nephropathy. J Urol 2001;165:210-214.

21 Girasole G, Jilka R.L, Passeri G, Boswell S, Boder G, Williams DC, Manolagas SC: 17 $\beta$ estradiol inhibits interleukin-6 production by bone marrow-derived stromal cells and osteoblasts in vitro: A potential mechanism for the antiosteoporotic effect of estrogens. J Clin Invest 1992;89:883-891. 